\title{
PENGEMBANGAN AGROWISATA BERBASIS MASYARAKAT DI KELURAHAN RURUKAN DAN RURUKAN I KECAMATAN TOMOHON TIMUR PROVINSI SULAWESI UTARA
}

\section{Community-Based Agrowisata Development In Land And Local Village I Tomohon District East North Sulawesi Province}

\author{
Meilany Rosita Lengkong ${ }^{1)}$, Made Antara ${ }^{2)}$, I Ketut Surya Diarta ${ }^{3)}$ \\ ${ }^{1)}$ Mahasiswa Program Studi Magister Agribisnis, Program Pascasarjana, Universitas Udayana \\ ${ }^{2,3}$ Staf Dosen Program Studi Magister Agribisnis, Program Pascasarjana, Universitas Udayana
}

Email : meilanylengkong@gmail.com

\begin{abstract}
One of the alternative tourism destinations in Tomohon City is agrotourism in Rurukan and Rurukan I District, East Tomohon Sub-District, North Sulawesi Province. Agrotourism has potential to be developed due to the strategic location, the location is in the highland with beautiful scenery, they have several horticultural activities, as well as cultural diversity that has become a great tourist attraction. The informant of this study were selected using purposive sampling that based on several specified criteria in accordance with the study objectives. Data collection methods were carried by conducting FGD (Focus Group Discussion). Data analysis methods were using descriptive analysis, SWOT and QSPM. The results showed that the main potential of community-based agrotourism development in Rurukan and Rurukan I District is the attraction aspect, including horticulture development centers, agriculture and regional culture, food and beverages processed agricultural products, tourist sites, traditional art, and art performances. The SWOT matrix result showed several alternatives strategic, including agriculture and local culture development and conservation; promotion of the agrotourism area; comfort and security maintenance in the area; agrotourism extension; agrotourism development and skill trainning; quality and quantity improvement on agrotourism location; and also human resource skill improvement. The priority strategy based on QSPM analysis is the agriculture and local culture development and conservation. Community, in this case farmers, and local government should be able to utilize the strengths and opportunities of the agrotourism potential to be able to minimize the existing weaknesses and threats. Based on the study, the recommendation including conservation on agricultural culture, traditional customs and regional culture, create and implement agrotourism activities, also both community and the government should prepare their-selves as skilled and innovative agrotourism players.
\end{abstract}

Keywords : Agrotourism, Community Based, Strategy

\begin{abstract}
ABSTRAK
Salah satu tujuan wisata alternatif di Kota Tomohon adalah agrowisata di Kabupaten Rurukan dan Rurukan I, Kecamatan Tomohon Timur, Provinsi Sulawesi Utara. Agrowisata memiliki potensi untuk dikembangkan karena lokasi yang strategis, lokasi berada di dataran tinggi dengan pemandangan yang indah, mereka memiliki beberapa kegiatan hortikultura, serta keanekaragaman budaya yang telah menjadi daya tarik wisata yang hebat. Informan penelitian ini dipilih menggunakan purposive sampling yang didasarkan pada beberapa kriteria yang ditentukan sesuai dengan tujuan penelitian. Metode pengumpulan data dilakukan dengan melakukan FGD (Focus Group Discussion). Metode analisis data menggunakan analisis deskriptif, SWOT dan QSPM. Hasil penelitian menunjukkan bahwa potensi utama pengembangan agrowisata berbasis masyarakat di Kabupaten Rurukan dan Rurukan I adalah aspek daya tarik, termasuk pusat pengembangan hortikultura, pertanian dan budaya daerah, produk pertanian olahan makanan dan minuman, lokasi wisata, seni tradisional, dan pertunjukan seni . Hasil matriks SWOT menunjukkan beberapa alternatif strategi, termasuk pertanian dan pengembangan budaya lokal dan konservasi; promosi kawasan agrowisata; pemeliharaan kenyamanan dan keamanan di area tersebut; perluasan agrowisata; pengembangan agrowisata dan pelatihan keterampilan; peningkatan kualitas dan kuantitas di lokasi agrowisata; dan juga peningkatan keterampilan sumber daya manusia. Strategi prioritas berdasarkan analisis QSPM adalah pengembangan dan konservasi budaya dan budaya lokal. Masyarakat, dalam hal ini petani, dan pemerintah daerah harus dapat memanfaatkan kekuatan dan peluang potensi agrowisata untuk dapat meminimalkan kelemahan dan ancaman yang ada. Berdasarkan studi tersebut, rekomendasi termasuk konservasi pada budaya pertanian, adat istiadat tradisional dan budaya daerah, membuat dan melaksanakan kegiatan
\end{abstract}


agrowisata, juga masyarakat dan pemerintah harus mempersiapkan diri sebagai pemain agrowisata yang terampil dan inovatif.

Kata kunci: Agrowisata, Berbasis Masyarakat, Strategi

\section{PENDAHULUAN}

\section{Latar Belakang}

Kota Tomohon merupakan bagian dari Provinsi Sulawesi Utara yang memiliki peluang untuk dikembangkan sebagai daerah agrowisata. Di sebelah timur Kota Tomohon terdapat lokasi agrowisata dengan hamparan kebun pertanian yang dikelola oleh masyarakat setempat secara tradisional. Lokasinya berada di Kelurahan Rurukan dan Rurukan I.

Kelurahan Rurukan dan Rurukan I terkenal dengan daerah penghasil sayur-sayuran (wortel, kubis, sawi/petsai, batang bawang dan brokoli). Agrowisata di Kelurahan Rurukan dan Rurukan I merupakan daerah potensial untuk dijadikan sebagai kawasan agrowisata berbasis masyarakat. Hal ini dibuktikan dengan peran aktif masyarakat untuk terus melestarikan budaya daerah melalui pelaksanaan kegiatan daerah yang menampilkan berbagai macam kebudayaan yang dimiliki oleh masyarakat di Kelurahan Rurukan dan Rurukan I. Selain itu, peluang lainnya terletak pada letak lokasi yang strategis dengan beberapa alternatif akses jalan dari berbagai daerah untuk menuju ke lokasi tersebut. Faktor-faktor tersebut yang menjadi daya tarik investor untuk memanfaatkannya sebagai peluang bisnis. Namun di sisi lain, hal ini dapat menjadi suatu ancaman bagi kehidupan masyarakat setempat apabila masyarakat dan pemerintah tidak siap dalam hal pemberdayaan sumberdaya manusia. Pengembangan sumberdaya manusia perlu dilakukan dengan peningkatan keterampilan dan ilmu pengetahuan sehingga dapat memaksimalkan penggunaan potensi daerahnya untuk dijadikan sebagai kawasan agrowisata berbasis masyarakat. Maka, perlu dilakukan analisis untuk dapat merumuskan strategi pengembangan agrowisata berbasis masyarakat di Kelurahan Rurukan dan Rurukan I.

\section{Tujuan Penelitian}

Tujuan penelitian ini adalah mendeskripsikan potensi agrowisata berbasis masyarakat di Kelurahan Rurukan dan Rurukan I, merumuskan alternatif strategi yang tepat untuk pengembangan agrowisata berbasis masyarakat di Kelurahan Rurukan dan Rurukan I, dan menentukan prioritas strategi untuk pengembangan agrowisata berbasis masyarakat di Kelurahan Rurukan dan Rurukan I, Kecamatan Tomohon Timur, Provinsi Sulawesi Utara.

\section{METODE PENELITIAN}

\section{Lokasi Penelitian}

Penelitian ini dilakukan di Kelurahan Rurukan dan Rurukan I, Kecamatan Tomohon Timur, Provinsi Sulawesi Utara.

\section{Informan Penelitian}

Informan penelitian disesuaikan dengan tujuan penelitian dan dipilih berdasarkan pertimbangan bahwa informan mengetahui dan mengerti serta dapat memberikan informasi yang dibutuhkan dalam penelitian. Informan dalam penelitian ini dipilih secara purposive sampling yaitu memilih informan kunci berdasarkan tujuan penelitian. Jumlah informan kunci penelitian untuk mengikuti FGD yang dipilih adalah sebanyak 12 orang.

\section{Instrumen Penelitian}

Instrumen penelitian yang digunakan dalam penelitian ini adalah menggunakan kuesioner sebagai pedoman wawancara, panduan untuk melaksanakan FGD, serta penggunaan kamera dan alat perekam video untuk dokumentasi kegiatan penelitian sebagai pelengkap data.

\section{Metode dan Teknik Pengumpulan Data}

Metode dan teknik pengumpulan data yang digunakan adalah observasi yaitu melakukan peninjauan langsung ke lokasi penelitian dengan tujuan untuk memperoleh gambaran mengenai potensi pengembangan agrowisata di Kelurahan Rurukan dan Rurukan I, wawancara dengan menggunakan pedoman wawancara dan kuesioner untuk mengetahui potensi agrowisata serta faktorfaktor yang berpengaruh terhadap pengembangan agrowisata di Kelurahan Rurukan dan Rurukan I, dokumentasi literatur, publikasi yang berkaitan dengan masalah penelitian dan pengambilan fotofoto di lokasi penelitian, serta melaksanakan Focus Group Discussion (FGD) untuk mendorong peserta FGD agar mau berpartisipasi aktif dalam diskusi dan menyampaikan hal-hal yang dianggap penting sehubungan dengan tujuan penelitian.

\section{Metode dan Teknik Analisis Data}

Penelitian ini menggunakan metode dan teknik analisis data yang terdiri dari analisis deskriptif, analisis faktor internal-eksternal (analisis IE), analisis SWOT dan QSPM.

\section{HASIL DAN PEMBAHASAN}

Meilany, et al., Pengembangan..|25 


\section{Deskripsi Potensi Agrowisata di Kelurahan Rurukan dan Rurukan I}

Potensi agrowisata di Kelurahan Rurukan dan Rurukan I telah mengembangkan aspek 4A yakni attraction (atraksi), accessibility (aksessibilitas), amenity (amenitas), dan ancillary (kelembagaan). Aspek attraction (atraksi) terdiri dari sentra pengembangan hortikultura, budaya pertanian dan budaya daerah (budaya Mapalus dan Blasteng), makanan dan minuman hasil produk olahan pertanian (kue cucur, nasi jaha, waji, gula batu/gula merah, saguer, captikus), adanya empat lokasi wisata (Gunung Mahawu, Puncak Rurukan, Puncak Temboan, Sparta Stable), kesenian tradisional (tarian Ma'zani, tarian Maengket, tarian Kabasaran, tarian Katrili, alat musik Kolintang, Tetengkoren, Musik Gesek dan Musik Bambu), serta kegiatan tahunan Kelurahan Rurukan dan Rurukan I dalam bentuk pentas seni rakyat. Berdasarkan aspek accessibility (aksesibilitas), Kelurahan Rurukan dan Rurukan I merupakan daerah yang letak lokasinya strategis. Akses jalan menuju kawasan daerah tersebut dapat dilalui dari berbagai daerah. Kondisi jalan juga sudah diaspal sehingga mempermudah perjalanan wisatawan yang datang berkunjung ke lokasi.
Sarana transportasi umum yang tersedia terdiri dari mobil angkutan umum dan motor (ojek). Dilihat dari aspek amenity (amenitas), terdapat fasilitas pendukung dalam bentuk tempat penginapan sederhana yang tersedia di lokasi wisata Puncak Temboan, fasilitas camping di lokasi wisata Sparta Stable, warung makan dan cafe di masing-masing lokasi wisata dan juga ada warung makan yang letaknya di sekitar pemukiman masyarakat, serta sarana kesehatan berupa puskesmas, bahkan terdapat pos polisi dan pos kamling untuk menjaga keamanan. Sedangkan dilihat dari aspek ancillary (kelembagaan), dibentuk kelompok petugas keamanan lingkungan masyarakat (linmas), pembentukan sanggar seni budaya, ada juga beberapa program pemerintah setempat yang bekerjasama dengan dinas terkait dalam pelaksanaan seminar atau pelatihan.

Strategi Pengembangan Agrowisata Berbasis Masyarakat di Kelurahan Rurukan dan Rurukan I

Berdasarkan hasil penelitian yang dilakukan, maka faktor lingkungan internal dan eksternal dalam pengembangan agrowisata berbasis masyarakat di Kelurahan Rurukan dan Rurukan I adalah sebagai berikut:

Tabel 1. Identifikasi Variabel dan Indikator Faktor Lingkungan Internal pada Pengembangan Agrowisata Berbasis Masyarakat di Kelurahan Rurukan dan Rurukan I

1. Produk pertanian hortikultura (sayur-sayuran) adalah produk utama yang dihasilkan

2. Sistem pertanian konvensional yang masih dilestarikan masyarakat

3. Budaya Mapalus (gotong royong)

4. Kelurahan Rurukan dan Rurukan I memiliki potensi pertanian dan pariwisata

Kekuatan yang berpeluang untuk dikembangkan (keindahan alam dan udara yang sejuk)

5. Sarana jalan melalui beberapa akses daerah

6. Budaya etnis yang dilestarikan masyarakat

7. Atraksi budaya berupa pagelaran seni yang mulai diselenggarakan setiap tahun sejak tahun 2017

8. Keamanan lingkungan daerah dan objek wisata

9. Adanya beberapa objek wisata

Kelemahan

1. Kurangnya keterampilan sumberdaya manusia (keterampilan kerajinan tangan dan keterampilan berbahasa asing)

2. Masyarakat belum paham benar tentang ruang lingkup agrowisata

3. Kurangnya jasa angkutan (mobil) untuk mengantar langsung ke lokasi wisata

4. Masih kurang mengadakan promosi

5. Ciri khas dan sejarah daerah yang belum di-expose

6. Belum ada toko-toko souvenir khas daerah dan tempat penginapan 
Tabel 2. Identifikasi Variabel dan Indikator Faktor Lingkungan Eksternal pada Pengembangan Agrowisata Berbasis Masyarakat di Kelurahan Rurukan dan Rurukan I

\begin{tabular}{|c|c|}
\hline Variabel & Indikator \\
\hline Peluang & $\begin{array}{l}\text { 1. Terdapat beberapa objek wisata yang berdekatan dengan harga tiket } \\
\text { masuk yang terjangkau. } \\
\text { 2. Partisipasi dan peran aktif masyarakat dalam melestarikan budaya dan } \\
\text { adat yang menjadi ciri khas daerah. } \\
\text { 3. Kelurahan Rurukan dan Rurukan I ditetapkan oleh Pemerintah Kota } \\
\text { sebagai destinasi wisata di Kota Tomohon. } \\
\text { 4. Meningkatnya kunjungan wisatawan. } \\
\text { 5. Letak dan jarak lokasi strategis (bandara, pusat kota, pasar extreme, } \\
\text { 6. Dan lain-lain). }\end{array}$ \\
\hline Ancaman & $\begin{array}{l}\text { 1. Pengaruh masuknya budaya dari luar. } \\
\text { 2. Wisatawan yang lebih terpusat di daerah kota. } \\
\text { 3. Terjadi alih fungsi lahan pertanian menjadi objek wisata milik swasta. } \\
\text { 4. Persaingan antar objek wisata milik swasta. }\end{array}$ \\
\hline
\end{tabular}

Tabel 3. Penghitungan Matriks Evaluasi Faktor Internal Strategi Pengembangan Agrowisata Berbasis Masyarakat di Kelurahan Rurukan dan Rurukan I

\begin{tabular}{|c|c|c|c|c|}
\hline \multicolumn{5}{|c|}{ Faktor Internal } \\
\hline No. & Kekuatan & Bobot & Rating & Skor \\
\hline 1 & $\begin{array}{l}\text { Produk pertanian hortikultura (sayur-sayuran) adalah produk } \\
\text { utama yang dihasilkan }\end{array}$ & 0,055 & 4 & 0,22 \\
\hline 2 & $\begin{array}{l}\text { Sistem pertanian konvensional yang masih dilestarikan } \\
\text { masyarakat }\end{array}$ & 0,05 & 3 & 0,15 \\
\hline 3 & Budaya Mapalus (gotong royong) & 0,05 & 4 & 0,2 \\
\hline 4 & $\begin{array}{l}\text { Kelurahan Rurukan dan Rurukan I memiliki potensi pertanian } \\
\text { dan pariwisata yang berpeluang untuk dikembangkan } \\
\text { (keindahan alam dan udara yang sejuk) }\end{array}$ & 0,065 & 4 & 0,26 \\
\hline 5 & Sarana jalan melalui beberapa akses daerah & 0,055 & 3 & 0,165 \\
\hline 6 & Budaya etnis yang dilestarikan masyarakat & 0,06 & 3 & 0,18 \\
\hline 7 & $\begin{array}{l}\text { Atraksi budaya berupa pagelaran seni yang mulai } \\
\text { diselenggarakan setiap tahun sejak tahun } 2017\end{array}$ & 0,055 & 3 & 0,165 \\
\hline 8 & Keamanan lingkungan daerah dan objek wisata & 0,055 & 3 & 0,165 \\
\hline 9 & Adanya beberapa objek wisata & 0,055 & 3 & 0,165 \\
\hline \multicolumn{5}{|c|}{ Kelemahan } \\
\hline 1 & $\begin{array}{l}\text { Kurangnya keterampilan sumberdaya manusia (keterampilan } \\
\text { kerajinan tangan dan keterampilan berbahasa asing) }\end{array}$ & 0,07 & 3 & 0,21 \\
\hline 2 & $\begin{array}{l}\text { Masyarakat belum paham benar tentang ruang lingkup } \\
\text { agrowisata }\end{array}$ & 0,07 & 3 & 0,21 \\
\hline 3 & $\begin{array}{l}\text { Kurangnya jasa angkutan (mobil) untuk mengantar langsung ke } \\
\text { lokasi wisata }\end{array}$ & 0,1 & 2 & 0,2 \\
\hline 4 & Masih kurang mengadakan promosi & 0,09 & 3 & 0,27 \\
\hline 5 & Ciri khas dan sejarah daerah yang belum di-expose & 0,08 & 2 & 0,16 \\
\hline 6 & $\begin{array}{l}\text { Belum ada toko-toko souvenir khas daerah dan tempat } \\
\text { penginapan }\end{array}$ & 0.09 & 3 & 0,27 \\
\hline \multicolumn{2}{|r|}{ Total Kekuatan + Kelemahan } & 1 & 46 & 2,99 \\
\hline
\end{tabular}


Tabel 4. Penghitungan Matriks Evaluasi Faktor Eksternal Strategi Pengembangan Agrowisata Berbasis Masyarakat di Kelurahan Rurukan dan Rurukan I

\begin{tabular}{|c|c|c|c|c|}
\hline \multicolumn{5}{|c|}{ Faktor Eksternal } \\
\hline No. & Peluang & Bobot & Rating & Skor \\
\hline 1 & $\begin{array}{l}\text { Terdapat beberapa objek wisata yang berdekatan dengan harga tiket } \\
\text { masuk yang terjangkau }\end{array}$ & 0,08 & 4 & 0,32 \\
\hline 2 & $\begin{array}{l}\text { Partisipasi dan peran aktif masyarakat dalam melestarikan budaya dan } \\
\text { adat yang menjadi ciri khas daerah }\end{array}$ & 0,07 & 3 & 0,21 \\
\hline 3 & $\begin{array}{l}\text { Kelurahan Rurukan dan Rurukan I ditetapkan oleh Pemerintah Kota } \\
\text { sebagai destinasi wisata di Kota Tomohon }\end{array}$ & 0,08 & 3 & 0,24 \\
\hline 4 & Meningkatnya kunjungan wisatawan & 0,09 & 4 & 0,36 \\
\hline 5 & Letak \& jarak lokasi strategis (bandara, pusat kota, pasar extreme, dll.) & 0,1 & 4 & 0,4 \\
\hline 6 & Daya tarik investor dari luar cukup besar & 0,08 & 3 & 0,24 \\
\hline \multicolumn{5}{|c|}{ Ancaman } \\
\hline 1 & Pengaruh masuknya budaya dari luar & 0,13 & 3 & 0,39 \\
\hline 2 & Wisatawan yang lebih terpusat di daerah kota & 0,14 & 3 & 0,42 \\
\hline 3 & Terjadi alih fungsi lahan pertanian menjadi objek wisata milik swasta & 0,12 & 2 & 0,24 \\
\hline 4 & Persaingan antar objek wisata milik swasta & 0,11 & 3 & 0,33 \\
\hline \multicolumn{2}{|r|}{ Total Peluang + Ancaman } & 1 & 32 & 3,15 \\
\hline
\end{tabular}

TOTAL SKOR BOBOT IFE

Kuat Rata-rata Lemah

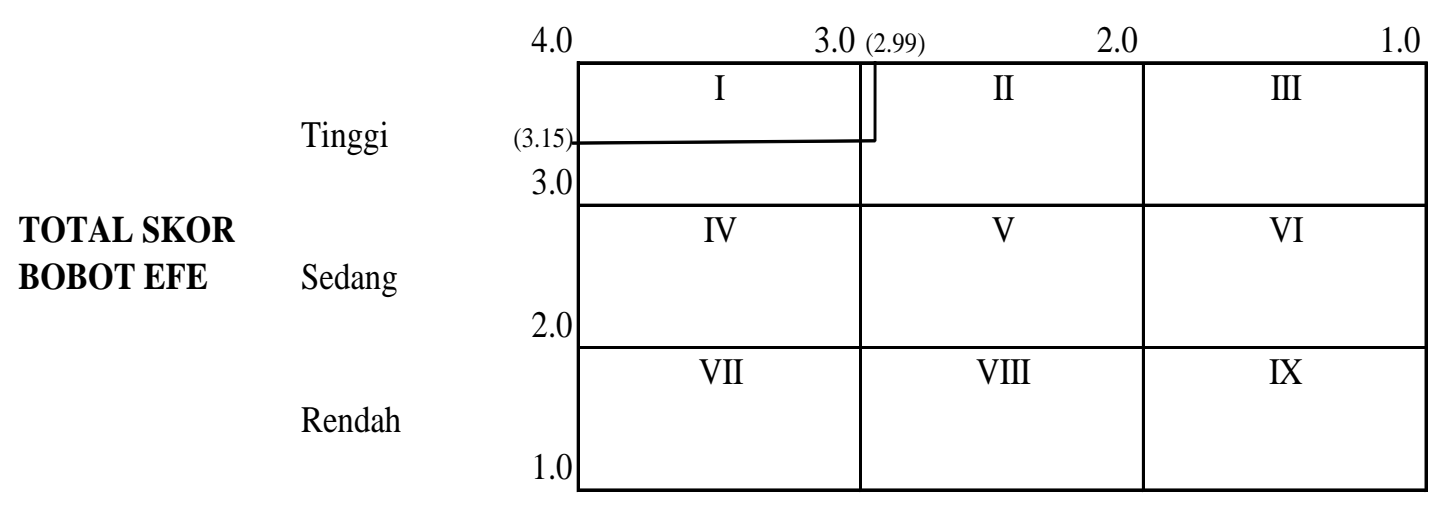

Gambar 1. Matriks Internal - Eksternal (I-E) Pada Pengembangan Agrowisata Berbasis Masyarakat di Kelurahan Rurukan dan Rurukan I 
Berdasarkan Gambar 1 menunjukkan bahwa posisi pengembangan agrowisata berbasis masyarakat di Kelurahan Rurukan dan Rurukan I dalam kondisi internal kuat dan kondisi eksternal yang dihadapinya tergolong tinggi. Strategi dengan sel tersebut adalah strategi pertumbuhan (growth strategy). Sel tersebut mengartikan bahwa pengembangan agrowisata berbasis masyarakat di Kelurahan Rurukan dan Rurukan I harus memanfaatkan kekuatan yakni melestarikan budaya pertanian dan budaya daerah serta memanfaatkan peluang yakni partisipasi dan peran aktif dari masyarakat yang saat ini terus dilakukan untuk mengembangkan potensi dan memacu pertumbuhan pengembangan agrowisata. Strategi pertumbuhan pada pengembangan agrowisata berbasis masyarakat di Kelurahan Rurukan dan Rurukan I artinya bahwa perlu adanya keterlibatan aktif dari masyarakat dan pemerintah untuk dapat mengembangkan kekuatan dan peluang dengan mendayagunakan potensi agrowisata yang ada di Kelurahan Rurukan dan Rurukan I. Peningkatan keterampilan sumberdaya manusia juga diperlukan untuk dapat mengelola sumberdaya alam yang ada sehingga masyarakat terlibat aktif dalam pengembangan agrowisata berbasis masyarakat di Kelurahan Rurukan dan Rurukan I.

Berdasarkan sintesis dari komponen-komponen SWOT, maka dihasilkan alternatif strategi sebagai berikut:

1. Strategi SO adalah strategi yang menggunakan kekuatan untuk memanfaatkan peluang yang ada. Berdasarkan matriks SWOT, strategi SO ada tiga yaitu :

a. Pengembangan dan pelestarian budaya pertanian dan budaya daerah.

b. Promosi daerah agrowisata.

c. Pemeliharaan kenyamanan dan keamanan lokasi.

2. Strategi ST adalah strategi yang menggunakan kekuatan untuk mengatasi atau meminimalisir ancaman. Berdasarkan matriks SWOT, strategi ST yaitu strategi penyuluhan tentang ruang lingkup agrowisata.

3. Strategi WO adalah strategi yang memperkecil kelemahan dengan memanfaatkan peluang. Berdasarkan matriks SWOT, strategi WO ada dua yaitu :

a. Pelatihan keterampilan dan pengembangan agrowisata.

b. Peningkatan kualitas dan kuantitas lokasi agrowisata.

4. Strategi WT adalah strategi untuk meminimalisasi kelemahan dan mengantisipasi ancaman. Berdasarkan matriks SWOT, strategi WT yaitu peningkatan keterampilan sumberdaya manusia.
Strategi Prioritas Pengembangan Agrowisata Berbasis Masyarakat di Kelurahan Rurukan dan Rurukan I

Berdasarkan hasil penghitungan QSPM maka dapat disusun prioritas strategi mana yang dapat diimplementasikan sesuai dengan peringkat pada masing-masing strategi. Hasil peringkat strategi sesuai dengan penghitungan tabel QSPM adalah sebagai berikut:

- Peringkat I adalah pengembangan dan pelestarian budaya pertanian dan budaya daerah.

- Peringkat II adalah pelatihan keterampilan dan pengembangan agrowisata.

- $\quad$ Peringkat III adalah penyuluhan tentang ruang lingkup agrowisata.

- Peringkat IV adalah peningkatan kualitas dan kuantitas lokasi agrowisata.

- Peringkat V adalah peningkatan keterampilan sumberdaya manusia.

- Peringkat VI adalah promosi daerah agrowisata.

- Peringkat VII adalah pemeliharaan keamanan dan kenyamanan lokasi.

\section{KESIMPULAN DAN SARAN}

\section{Kesimpulan}

Berdasarkan hasil penelitian yang telah dilakukan, maka kesimpulan yang diperoleh adalah sebagai berikut :

1. Potensi utama dalam aktivitas pengembangan agrowisata berbasis masyarakat di Kelurahan Rurukan dan Rurukan I adalah aspek atraksi, diantaranya sentra pengembangan hortikultura, budaya pertanian dan budaya daerah, makanan dan minuman hasil olahan produk pertanian, lokasi wisata, kesenian tradisional, serta pagelaran seni yang dilaksanakan setiap tahun.

2. Hasil analisis SWOT diperoleh beberapa alternatif strategi. Strategi SO adalah pengembangan dan pelestarian budaya pertanian dan budaya daerah, promosi daerah agrowisata, dan pemeliharaan keamanan dan kenyamanan lokasi. Strategi WO adalah pelatihan keterampilan dan pengembangan agrowisata serta peningkatan kualitas dan kuantitas lokasi agrowisata. Strategi ST adalah penyuluhan tentang ruang lingkup agrowisata. Strategi WT adalah peningkatan keterampilan sumberdaya manusia.

3. Hasil analisis QSPM menunjukkan bahwa strategi yang memiliki daya tarik paling tinggi dan menjadi prioritas utama adalah strategi pengembangan dan pelestarian budaya pertanian dan budaya daerah. Partisipasi dan 
peran aktif petani sebagai pelaku agrowisata menjadi faktor penunjang pengembangan agrowisata berbasis masyarakat di Kelurahan Rurukan dan Rurukan I.

\section{Saran}

Berdasarkan kesimpulan yang diperoleh dari hasil penelitian yang dilakukan, maka saran untuk pengembangan agrowisata berbasis masyarakat di Kelurahan Rurukan dan Rurukan I adalah sebagai berikut :

1. Masyarakat harus berpartisipasi aktif dalam melestarikan budaya pertanian dan budaya daerah. Perlu juga membentuk kelompok/lembaga untuk pengolahan produk pertanian untuk disajikan bahkan dijual bagi wisatawan sehingga dapat memberikan pendapatan tambahan bagi masyarakat petani.

2. Masyarakat dan pemerintah bekerjasama dalam pengembangan agrowisata berbasis masyarakat di Kelurahan Rurukan dan Rurukan I dengan membuat program berupa penataan lokasi agrowisata, menyediakan paket agrowisata bagi wisatawan, pemberdayaan masyarakat serta pengembangan budaya tradisional daerah. Perlu juga dilakukan promosi mengenai kawasan agrowisata berbasis masyarakat melalui kerjasama dengan agen-agen jasa (tour \& travel), Dinas Pariwisata Kota Tomohon, serta pelatihan keterampilan (kerajinan tangan dan keterampilan berbahasa asing).

3. Masyarakat dan pemerintah harus menjadi pelaku usaha agrowisata yang terampil, kreatif, mampu memanfaatkan teknologi pertanian dan promosi dalam pengembangan agrowisata berbasis masyarakat di Kelurahan Rurukan dan Rurukan I.

4. Rekomendasi untuk penelitian lanjutan adalah perlu dilakukan penelitian tentang analisis faktor yang mempengaruhi pengembangan agrowisata di Kelurahan Rurukan dan Rurukan I.

\section{DAFTAR PUSTAKA}

Antara, M. 2006. Modul Metodologi Penelitian Sosial. Denpasar : Universitas Udayana.

Balai Pengkajian Teknologi Pertanian Sulawesi Utara. 2013. Dalam Program KKP3N: IPB Sosialisasikan Pengembangan Agrowisata Terpadu di Kota Tomohon. Artikel dalam sulut.litbang.pertanian.go.id. Accessed October $9^{\text {th }} 2017$.

David, R. F. 2000. Manajemen Strategi. PT. Prendhalilindo: Jakarta.
Gulo, W. 2002. Metodologi Penelitian. Gramedia Widiasarana Indonesia : Jakarta.

Kotler, P. \& K. L. Keller. 2009. Manajemen Pemasaran. Edisi Ke-12 Jilid 1. PT. Macanan Jaya Cemerlang: Indonesia.

PT. Shiddiq Sarana Mulya, 2009. Laporan Akhir : Model Pengelolaan Agroekoturisme Oleh Koperasi. Jakarta.

Raco, J. R. 2010. Metode Penelitian Kualitatif : Jenis, Karakteristik dan Keunggulannya. PT. Grasindo : Jakarta.

Rangkuti, F. 2006. Analisis SWOT Teknik Membedah Kasus Bisnis. PT. Gramedia Pustaka Utama : Jakarta.

Rangkuti, F. 2013. SWOT Balanced Scorecard: Teknik Menyusun Strategi Korporat yang Efektif plus Cara Mengelola Kinerja dan Risiko. PT. Gramedia Pustaka Utama: Jakarta.

Suansri, P. 2003. Community Based Tourism Handbook. Thailand : REST Project.

Sugiyono. 2004. Business Research Methods. Alfabeta : Bandung.

Sulutindo, R. 2017. Agrowisata Rurukan Kota Tomohon. Artikel dalam Destinasi Sulut, Blog Kepariwisataan Sulawesi Utara.

Suwarsono, M., 2008. Manajemen Strategik Konsep dan Kasus. Sekolah Tinggi Ilmu Manajemen YKPN: Yogyakarta.

Umar, H. 2001. Strategic Management in Action : Konsep, Teori dan Teknik Menganalisis Manajemen Strategis. PT. Gramedia Pustaka Utama : Jakarta. 